\title{
Epidemiology of Staphylococcus aureus in patients with cystic fibrosis
}

\author{
C. BRANGER ${ }^{1 *}$, J. M. FOURNIER ${ }^{2}$, J. LOULERGUE ${ }^{3}$, A. BOUVET ${ }^{4}$, \\ PH. GOULLET ${ }^{1}$, A. BOUTONNIER ${ }^{2}$, C. DE GIALLULY ${ }^{3}$, G. COUETDIC ${ }^{5}$, \\ M. CHOMARAT ${ }^{6}$, M. C. JAFFAR-BANJEE ${ }^{7}$ AND P. MARIANI ${ }^{8}$ \\ ${ }^{1}$ Laboratoire de Microbiologie, Faculté de Médecine X. Bichat, Paris VII \\ ${ }^{2}$ Unité du Choléra et des Vibrions, Institut Pasteur, Paris \\ ${ }^{3}$ Laboratoire de Bactériologie, Hôpital Trousseau, Tours \\ ${ }^{4}$ Laboratoire de Microbiologie, Hôpital Hôtel-Dieu, Paris \\ ${ }^{5}$ Laboratoire de Microbiologie, Hôpital J. Minjoz, Besançon \\ ${ }^{6}$ Laboratoire de Bactériologie, Centre Hospitalier Lyon Sud, Pierre-Benite \\ ${ }^{7}$ Laboratoire de Biochimie-Bactériologie, Hôpital Renée Sabran, Giens, Hyères \\ ${ }^{8}$ Laboratoire de Microbiologie, Hôpital Robert Debré, Paris, France
}

\section{(Accepted 5 January 1994)}

\section{SUMMARY}

Seven hundred and thirty-four isolates of Staphylococcus aureus, recovered from the sputum of 238 cystic fibrosis patients in six French hospitals, were characterized by esterase electrophoretic typing, capsular polysaccharide serotyping and phage typing and tested against 14 antibiotics for sensitivity. Thirtyfour esterase electrophoretic types were found with a genotypic diversity coefficient of 0.91 . Five hundred and forty-eight $(78.7 \%)$ isolates produced capsular polysaccharide and $350(50 \cdot 3 \%)$ were type 8 . Four hundred and sixty isolates $(66.6 \%)$ were phage typable and $202(28 \cdot 2 \%)$ were lysed by group III bacteriophages. No esterase electrophoretic type, capsular type or phage type was specific to cystic fibrosis. Isolates belonged to a wide range of types, similar to strains acquired outside hospitals. Eighty-five patients had three or more consecutive isolates over at least 6 months. The ability of $S$. aureus to persist for long periods of time has been demonstrated in $73 \%$ of them. Methicillin-resistance was encountered among 73 strains $(9 \cdot 8 \%)$ which were also multiresistant. Two hundred and eighty-nine $(39.9 \%)$ strains were sensitive to all antibiotics tested except to penicillin. Pristinamycin and co-trimoxazole were the most effective antibiotics. These results could contribute to the elaboration of a rational approach to the prophylaxis and therapy of respiratory staphylococcal infections in cystic fibrosis patients.

\section{INTRODCCTION}

Staphylococcus aureus is the second most persistent pathogen recovered from the respiratory tract of infected cystic fibrosis patients, especially those who are under

* Correspondence and reprint requests: Dr Catherine Branger, Laboratoire de Microbiologie, Hôpital Beaujon, 100 Boulevard du Général Leclerc, 92110 Clichy, France. 
the age of 10 years [1-4]. Colonization by $S$. aureus is usually followed by Pseudomonas aeruginosa the most persistent pathogen. Multiresistant strains of $S$. aureus have been shown to be infrequent in these patients $[5,6]$. Despite the availability of effective antistaphylococcal therapy, recurrent infections are common $[5,7,8]$. Little information is available on the epidemiology of $S$. aureus in cystic fibrosis patients and to our knowledge it has not been clearly demonstrated whether the same strain or different strains are responsible for repeated bronchopulmonary infections $[6,9,10]$.

Electrophoretic techniques are powerful tools for detecting genetic variations of enzymes. Variations in esterase electrophoretic patterns have made a significant contribution to the epidemiological analysis of $S$. aureus [11-13]. Capsular polysaccharides have been identified in clinical isolates of $S$. aureus [14-16] and studies have shown the predominance of capsular types 5 and 8 among clinical isolates in both the United States and Europe [14-17]. A similar predominance has also been found in cystic fibrosis patients [18]. Although phage typing can be limited by the occurrence of $S$. aureus strains that are not typable, this method has been traditionally used for epidemiological studies, and offers a high degree of discrimination [19].

We have used esterase electrophoretic typing, capsular typing and phage typing to investigate the epidemiology of $S$. aureus strains responsible for recurrent bronchopulmonary infections in cystic fibrosis patients. Sensitivity against a broad spectrum of antibiotics known to be active against staphylococci was also investigated.

\section{MATERIALS AND METHODS}

\section{Bacterial strains}

A total of 734 strains of $S$. aureus was collected from the clinical laboratories of six French hospitals [(Giens (A), Tours (B), Lyon (C), Paris (D and E) and Besançon (F)] between January 1984 and December 1991. The organisms were isolated from the sputum of 238 cystic fibrosis patients suffering from chronic or intermittent infections. Eighty-five patients provided three or more consecutive isolates (up to 28 ) recovered over a period of at least 6 months (up to 3 years).

\section{Esterase electrophoretic typing}

The electrophoretic mobility patterns of esterases A, B and C were investigated as previously described $[12,20]$ with the following modifications. Strains were grown overnight at $37^{\circ} \mathrm{C}$ in $25 \mathrm{ml}$ brain heart infusion broth (Sanofi, Diagnostics Pasteur, France). The bacteria were collected by centrifugation. The pellets were washed in $0.075 \mathrm{M}$ Tris $0.06 \mathrm{M}$ glycine buffer, $\mathrm{pH} 8.7$ and suspended in $2.0 \mathrm{ml}$ of the same buffer. They were lysed by incubation with $100 \mu \mathrm{g}$ lysostaphin (Sigma Chemical Co.) at $37^{\circ} \mathrm{C}$ for $1 \mathrm{~h}$, with vigorous shaking and centrifuged at $20000 \mathrm{~g}$ for $10 \mathrm{~min}$ at $4^{\circ} \mathrm{C}$. The extracts were analysed by polyacrylamide-agarose gel electrophoresis on a $5 \%$ acrylamide and $0.8 \%$ agarose gel in a $0.01 \mathrm{~m}$ Tris, $0.35 \mathrm{~m}$ glycine buffer, pH 8.7. Electrophoresis was performed at a constant value of $7 \mathrm{~V} . \mathrm{cm}^{-1}$ until the dye marker had run $11 \mathrm{~cm}$. Esterases were stained in the gel with $\alpha$-naphthyl propionate as substrate. 


\section{Capsular polysaccharide typing}

Capsular polysaccharide types 5 and 8 were detected as previously described [21]. Briefly, bacteria were grown overnight at $37{ }^{\circ} \mathrm{C}$ on Columbia Agar slants (Difco Laboratories, Detroit, MI), suspended in phosphate buffered saline and autoclaved at $121^{\circ} \mathrm{C}$ for $1 \mathrm{~h}$. Debris was removed by centrifugation and the polysaccharides in the supernatant were detected by inhibition enzyme-linked immunosorbent assay using purified capsular polysaccharide 8 or 5 and the corresponding monoclonal antibodies. Strains lacking both type 5 and type 8 capsular polysaccharides were designated as non-typable.

\section{Phage typing}

The international set of 23 phage types (group 1:29,52,52A, 79 and 80; group II : $3 \mathrm{~A}, 3 \mathrm{C}, 55$ and 71 ; group III : $6,42 \mathrm{E}, 47,53,54,75,77,83 \mathrm{~A}, 84$ and 85 ; and miscellaneous 81, 94, 95 and 96) was applied using standard methods [19]. An additional experimental phage, $54 \mathrm{~A}$, was also tested. Isolates were typed at the routine test dilution and at $\mathbf{1 0 0}$-fold higher concentration. Only reactions showing major lysis were considered. Two isolates are considered to have different phage types when one is lysed by at least two phages which produce no lysis of the other.

\section{Antibiotic sensitivity}

Strains were examined for antibiotic sensitivity by disk diffusion test on Muller Hinton agar (Sanofi, Diagnostics Pasteur, France), according to the guidelines of the antibiogram committee of the French Society for Microbiology [24]. The antibiotics concerned were penicillin, oxacillin (for the detection of methicillin sensitivity), gentamicin, tobramycin, kanamycin, tetracycline, erythromycin, clindamycin, pristinamycin, pefloxacin, co-trimoxazole, fosfomycin, fusidic acid and rifampicin. Penicillinase activity was detected with the cefinase test (BioMérieux, France).

\section{Genotypic diversity}

The genotypic diversity for a zymotype was estimated by the formula $h=$ $1-\Sigma x_{i}^{2}[n /(n-1)]$ where $x_{i}$ is the frequency of the $i$ th zymotype and $n$ the number of zymotypes [22, 23].

\section{Statistical analysis}

Statistical significance was determined with the chi-square test with Yates correction when indicated.

\section{RESULTS}

\section{Esterase electrophoretic typing}

All the 734 isolates tested were typable by this method, and 34 distinct combinations of electromorphs for esterases A, B and C (zymotypes) were found. In addition to 19 zymotypes described previously [12, 13, 25], 14 new zymotypes were distinguished: $4 \mathrm{a}, 10 \mathrm{c}, 11 \mathrm{~b}, 14 \mathrm{a}, 14 \mathrm{~b}, 22,23,24,24 \mathrm{a}, 25,26,27,28,33$. Only one isolate was used for analysis for patients having repeated isolates of the same 
Table 1. Hospital zymotype distribution

\begin{tabular}{|c|c|c|c|c|c|c|c|c|}
\hline \multirow[b]{2}{*}{ Zymotypes } & \multicolumn{6}{|c|}{$\begin{array}{l}\text { Number of strains } \\
\text { in each hospital* }\end{array}$} & \multicolumn{2}{|c|}{ Total strains } \\
\hline & $\mathrm{A}$ & $\mathrm{B}$ & $\mathrm{C}$ & $\mathrm{D}$ & $\mathrm{E}$ & $\mathrm{F}$ & No. & $\%$ \\
\hline 1 & & 2 & 1 & 1 & & & 4 & $1 \cdot 10$ \\
\hline 2 & 7 & 1 & 3 & 3 & & & 14 & $3 \cdot 85$ \\
\hline $4 \mathrm{a}$ & 1 & 1 & & & & & 2 & 0.55 \\
\hline 5 & 16 & 6 & 4 & 4 & & & 30 & $8 \cdot 26$ \\
\hline 6 & 4 & 1 & 1 & 6 & 1 & & 13 & $3 \cdot 58$ \\
\hline 7 & 22 & 11 & 11 & 7 & & 1 & 52 & $14 \cdot 32$ \\
\hline $7 \mathrm{a}$ & 1 & & & & & & 1 & $0 \cdot 27$ \\
\hline $9 \mathrm{a}$ & 2 & 2 & 3 & & 1 & & 8 & $2 \cdot 20$ \\
\hline 10a & 20 & 3 & 5 & 8 & & 1 & 37 & $10 \cdot 19$ \\
\hline $10 \mathrm{c}$ & 1 & & & & & & 1 & $0 \cdot 27$ \\
\hline 11 & 20 & 6 & 4 & 3 & & & 33 & $9 \cdot 09$ \\
\hline $11 \mathrm{a}$ & & & 1 & & & & 1 & $0 \cdot 27$ \\
\hline $11 \mathrm{~b}$ & 1 & & & & & & 1 & $0 \cdot 27$ \\
\hline 12 & & 1 & 1 & & & & 2 & 0.55 \\
\hline 14 & 25 & 10 & 10 & 7 & 1 & 2 & 55 & $15 \cdot 15$ \\
\hline $14 \mathrm{a}$ & 5 & 2 & 1 & 1 & & 1 & 10 & $2 \cdot 75$ \\
\hline $14 \mathrm{~b}$ & & & & 1 & & & 1 & $0 \cdot 27$ \\
\hline 15 & 2 & 1 & 1 & 2 & 1 & & 7 & 1.92 \\
\hline 16 & 10 & 6 & & 3 & & & 19 & $5 \cdot 23$ \\
\hline $16 \mathrm{a}$ & 11 & 8 & 7 & 3 & 1 & 2 & 32 & $8 \cdot 81$ \\
\hline $17 \mathrm{a}$ & 1 & & & & & & 1 & $0 \cdot 27$ \\
\hline $17 \mathrm{~b}$ & 1 & 2 & & 1 & & & 4 & $1 \cdot 10$ \\
\hline 19 & 1 & & 1 & & & & 2 & 0.55 \\
\hline 20 & & & & 1 & & & 1 & $0 \cdot 27$ \\
\hline 21 & & 1 & & & & & 1 & $0 \cdot 27$ \\
\hline 22 & & 1 & & & & & 1 & $0 \cdot 27$ \\
\hline 23 & 2 & 2 & 2 & 2 & 1 & & 9 & $2 \cdot 47$ \\
\hline 24 & 1 & 1 & & 1 & & & 3 & 0.82 \\
\hline $24 \mathrm{a}$ & 2 & & & & & & 2 & 0.55 \\
\hline 25 & 2 & & & 1 & & & 3 & 0.82 \\
\hline 26 & 1 & & & & & & 1 & $0 \cdot 27$ \\
\hline 27 & 3 & 3 & 1 & 2 & & & 9 & $2 \cdot 47$ \\
\hline 28 & & & 1 & & & & 1 & $0 \cdot 27$ \\
\hline 33 & 2 & & & & & & 2 & 0.55 \\
\hline
\end{tabular}

* One strain only was considered for patient having repeated isolates of the same zymotype.

zymotype (Table 1). This provided a total of 363 strains. The overall genotypic diversity coefficient was 0.91 . The most frequent types, 14, 7, 10a, 11, 16a and 5 accounted for $15,14,10,9,9$ and $8 \%$ of the strains, respectively. The frequencies of the zymotypes did not differ significantly between hospitals $(P>0 \cdot 2)$, except for zymotype 6 which was more frequent among the strains isolated from patients in hospital D $(P<0 \cdot 01)$ (Table 1). Five patients provided two strains with different zymotypes in a single sample: this occurred once for four patients and three times for one patient.

\section{Capsular typing}

A total of 696 isolates was studied, of which $350(50 \cdot 3 \%)$ were capsular type 8 , $198(28.4 \%)$ were capsular type 5 and $148(21 \cdot 3 \%)$ were non-typable. 
Table 2. Relationship between phage types and zymotypes

\begin{tabular}{|c|c|c|c|c|c|c|c|c|}
\hline \multirow[b]{2}{*}{ Zymotypes } & \multicolumn{8}{|c|}{ Number of strains in each groups of bacteriophages } \\
\hline & I & II & III & $94 / 96$ & 95 & 81 & $\operatorname{Mix} \mathrm{G}^{*}$ & $\mathrm{NT} \dagger$ \\
\hline 1 & & & & & & & 1 & 4 \\
\hline 2 & 1 & 17 & 1 & & & & & \\
\hline $4 \mathrm{a}$ & & & 1 & & 7 & & & \\
\hline 5 & 1 & & 50 & & 1 & & 5 & 12 \\
\hline 6 & & & 18 & & & 1 & 1 & 5 \\
\hline 7 & & 29 & 2 & & 3 & & 3 & 41 \\
\hline $7 \mathrm{a}$ & & & 1 & & & & & \\
\hline $9 \mathrm{a}$ & & & 14 & & & & & 2 \\
\hline $10 \mathrm{a}$ & & 2 & 13 & & 23 & & 2 & 14 \\
\hline $10 \mathrm{c}$ & & & & & 1 & & & \\
\hline 11 & & & 59 & & & & 10 & 18 \\
\hline $11 \mathrm{a}$ & & & 2 & & & & & \\
\hline $11 \mathrm{~b}$ & & & 1 & & & & & \\
\hline 12 & & & 1 & & & & & 1 \\
\hline 14 & 28 & & 18 & & 1 & 9 & 9 & 50 \\
\hline $14 \mathrm{a}$ & 4 & 1 & 1 & & & 1 & & 35 \\
\hline 15 & & 18 & & & & & & 3 \\
\hline 16 & 2 & & 3 & & & 1 & & 13 \\
\hline $16 \mathrm{a}$ & & & & 62 & & & & 3 \\
\hline $17 \mathrm{~b}$ & & 2 & & & & & & 3 \\
\hline 19 & & & 4 & & & & & \\
\hline 21 & & 1 & & & & & & \\
\hline 22 & & & 1 & & & & & 1 \\
\hline 23 & 1 & 1 & 2 & & & & & 11 \\
\hline 24 & & & & & & & & 3 \\
\hline $24 \mathrm{a}$ & & & & & & & & 3 \\
\hline 25 & & & 6 & & & & & \\
\hline 26 & & & 2 & & & & & \\
\hline 27 & & 8 & & & & & & 6 \\
\hline 28 & & & 2 & & & & & \\
\hline 33 & 1 & & & & & & & 3 \\
\hline Total of strains & 38 & 79 & 202 & 62 & 36 & 12 & 31 & 231 \\
\hline$\%$ strains & $5 \cdot 5$ & $11 \cdot 4$ & $29 \cdot 2$ & 9 & $5 \cdot 2$ & $1 \cdot 7$ & 4.5 & $33 \cdot 4$ \\
\hline
\end{tabular}

\section{Phage typing}

Of the 691 isolates typed, $460(66 \cdot 6 \%)$ were phage typable (Table 2). Two hundred and two $(29 \cdot 2 \%)$ isolates were lysed by group III bacteriophages and 79 $(11 \cdot 4 \%)$ by group II bacteriophages. Bacteriophages $81,94 / 96,95$ and group I bacteriophages lysed fewer than $10 \%$ of the isolates each. A small percentage $(3 \cdot 6 \%)$ of the isolates were lysed by phages belonging to several lytic groups.

\section{Correlation of the three typing methods}

Two strains with identical zymotype that were typable by capsular typing never had different capsular types. For example, all isolates of zymotypes 14, 10a and 7 were capsular type 8 and all isolates of zymotypes 16a, 11 and 5 were 
Table 3. Correlation between capsular types and esterase electrophoretic types

Capsular types

5

8
Zymotypes

$1,5,6,11,11 \mathrm{a}, 12,15,16 \mathrm{a}$

$2,4 \mathrm{a}, 7,9 \mathrm{a}, 10 \mathrm{a}, 14,14 \mathrm{a}, 16,17 \mathrm{~b}, 23,27,33$

Table 4. Distribution of zymotypes in the three groups of patients

\begin{tabular}{|c|c|c|c|}
\hline \multirow[b]{2}{*}{ Zymotypes } & \multicolumn{3}{|c|}{ Number of strains } \\
\hline & Group 1* & Group 2 & Group 3 \\
\hline 1 & - & - & 1 \\
\hline 2 & 1 & - & 4 \\
\hline $4 a$ & 1 & - & 1 \\
\hline 5 & 8 & - & 7 \\
\hline 6 & 2 & - & 1 \\
\hline 7 & 5 & 2 & 7 \\
\hline $9 \mathrm{a}$ & 2 & 1 & 3 \\
\hline $10 \mathrm{a}$ & 5 & 1 & 7 \\
\hline 11 & 7 & 2 & 8 \\
\hline 14 & 12 & 3 & 12 \\
\hline $14 \mathrm{a}$ & 2 & - & 1 \\
\hline 15 & 2 & - & - \\
\hline 16 & 1 & 1 & 2 \\
\hline $16 \mathrm{a}$ & 5 & 1 & 7 \\
\hline $17 \mathrm{~b}$ & - & - & 1 \\
\hline 19 & - & 1 & 1 \\
\hline 22 & - & 1 & - \\
\hline 23 & 1 & 1 & 2 \\
\hline 24 & - & - & 1 \\
\hline 26 & - & 1 & - \\
\hline 27 & 1 & -- & 2 \\
\hline 33 & - & - & 1 \\
\hline
\end{tabular}

* Group 1 and group 2: patients with persistent strains, group 3: patients with varying strains.

capsular type 5 (Table 3 ). Two strains phage-typable with identical zymotype could differ in their phage type, likewise two strains with identical phage type could differ in their zymotype (Table 2).

\section{Persistence of S. aureus strains}

Consecutive isolates were recovered from 26 patients over periods of 6-12 months, from 29 patients over periods of $12-18$ months, and from 30 patients over periods greater than 18 months. A minimum of three consecutive isolates was analysed per patient.

As all the strains were typable by the esterase electrophoretic technique and as the genotypic diversity obtained was satisfactory, the zymotype was used to divide the patients into three groups. One group of 55 patients had persistent strains of the same zymotype. Fifteen different zymotypes were identified (Table 4). Some patients had strains that persisted for over 2 years. The second group of seven patients included four patients whose strain type changed, each type persisted for 3-16 months, and three patients who had two strains of different types that persisted throughout the study. Eleven zymotypes were identified 
Table 5. Distribution of the 85 patients with 3 or more consecutive isolates over at least 6 months in the 6 hospitals

\begin{tabular}{crrrrrr} 
& \multicolumn{3}{c}{ Hospital (number of patients) } \\
\cline { 2 - 7 } Patients* & A & B & C & D & E & F \\
Group 1 & 22 & 9 & 16 & 5 & 2 & 1 \\
Group 2 & 2 & 2 & 2 & 0 & 1 & 0 \\
Group 3 & 10 & 5 & 7 & 1 & 0 & 0
\end{tabular}

* Group 1 and group 2 : patients with persistent strains, group 3: patients with varying strains.

(Table 4). Twenty-three patients in the third group had very variable strain populations with 19 different zymotypes (Table 4). Three to five strain types were recovered from each patient. However, according to capsular type and zymotype a single strain was found twice in the consecutive isolates from six patients and three times in the consecutive isolates from two patients. Seven patients had the strains with identical capsular type and zymotype that were either not phage typable or differed in phage type. Only one patient had a phage typable strain isolated at the end of the study that was identical by all three markers (capsular type 5, zymotype 11 and phage type $83 \mathrm{~A} / 85$ ) to a strain isolated at the beginning of the study.

The number of patients in all the hospitals having persistent strains (groups 1 and 2 ) was greater than the number of patients with very variable strains (group 3) (Table 5).

There was no statistical difference between the distribution of the major zymotypes (zymotypes 14, 7, 10a, 11, 16a, 5) among the persistent strains of groups 1 and 2 , among the variable strains of group 3 , or within the total population of strains studied $(P<0.50)$ (Tables 1 and 4$)$.

The phage type of the consecutive isolates from patients in groups 1 and 2 with persistent infections due to a single strain according to capsular type and zymotype were analysed (Tables 6 and 7 ). Thirty-six patients had consecutive isolates with the same phage type throughout the study (Table 6 ). The consecutive isolates from 13 patients had different phage types (Table 7) but 9 patients had consecutive isolates lysed by phages belonging to the same group III bacteriophage. The isolates from only four patients were lysed consecutively by phages of different groups (group I, group III and 81) (Table 7). Twenty patients had consecutive isolates which were not typable by phages.

\section{Antibiotic sensitivity}

The results of antibiotic sensitivity testing are given in Tables 8 and 9 . The majority of strains was resistant to penicillin. However, penicillinase activity was not detected in $168(22 \cdot 8 \%)$ strains. Seventy-three strains $(9 \cdot 8 \%)$ were resistant to oxacillin (methicillin). Besides penicillin, the highest rates of resistance were found against erythromycin $(18.1 \%)$, kanamycin $(14.5 \%)$ and tetracycline $(12 \cdot 3 \%)$. Two hundred and eighty-nine $(39 \cdot 3 \%)$ strains were sensitive to all antibiotics tested except penicillin. Six hundred and twenty-eight $(85.5 \%)$ strains were sensitive to all aminoglycosides. Methicillin-resistant strains were resistant 
Table 6. Characteristics of 36 persistent strains with stable phage types

\begin{tabular}{|c|c|c|c|c|c|}
\hline $\begin{array}{l}\text { Numbers of } \\
\text { patients }\end{array}$ & Hospital & $\begin{array}{l}\text { Capsular } \\
\text { type }\end{array}$ & Zymotype & $\begin{array}{l}\text { Lytic } \\
\text { group }\end{array}$ & Phage type \\
\hline 1 & B & 8 & 2 & II & $3 c / 55 / 71$ \\
\hline 1 & B & 8 & $4 a$ & 95 & 95 \\
\hline 1 & D & 5 & 5 & III & 75 \\
\hline 1 & D & NT & 5 & III & $6 / 47 / 54 / 75 / 83 \mathrm{~A} / 85$ \\
\hline 1 & A & NT & 5 & III & $83 \mathrm{~A} / 85$ \\
\hline 1 & B & NT & 5 & III & $42 \mathrm{E} / 47 / 54$ \\
\hline 2 & C & 8 & 7 & II & 71 \\
\hline 1 & B & 8 & 7 & II & 55 \\
\hline 2 & $\mathrm{C}$ & 8 & $9 \mathrm{a}$ & III & $83 \mathrm{~A} / 85$ \\
\hline 3 & C, D & 8 & $10 \mathrm{a}$ & 95 & 95 \\
\hline 3 & A & 5 & 11 & III & $83 \mathrm{~A}$ \\
\hline 1 & $\mathrm{C}$ & 5 & 11 & III & $42 / 47$ \\
\hline 5 & $\mathrm{~A}, \mathrm{C}, \mathrm{D}$ & 8 & 14 & I & 29 \\
\hline 1 & A & 8 & 14 & I & 52 \\
\hline 1 & C & 8 & 14 & 81 & 81 \\
\hline 1 & $\mathrm{C}$ & 8 & 14 & III & $75 / 85 / 54$ \\
\hline 2 & $\mathrm{~B}, \mathrm{E}$ & 5 & 15 & II & $3 \mathrm{~A}$ \\
\hline 6 & $\mathrm{~A}, \mathrm{~B}, \mathrm{C}, \mathrm{E}$ & 5 & $16 \mathrm{a}$ & $94 / 96$ & $94 / 96$ \\
\hline 1 & A & 8 & 19 & III & $75 / 83 \mathrm{~A} / 85$ \\
\hline 1 & A & 8 & 27 & II & $3 \mathrm{~A}$ \\
\hline
\end{tabular}

Table 7. Characteristics of 13 persistent strains with variable phage types

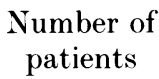

2
2
1
3
1
1
1
1
1

Hospital

A, C

$\mathrm{A}, \mathrm{E}$

A

$\mathrm{A}, \mathrm{B}, \mathrm{C}$

A

A

C

A

A

Capsular
type

5

5

8

5

8

5

8

8

8

$\begin{array}{cl}\text { Zymotype } & \text { Lytic } \\ \text { group } \\ 5 & \text { III } \\ 6 & \text { III } \\ 10 \mathrm{a} & \text { III } \\ 11 & \text { III } \\ 14 & \text { III } \\ 11 & \text { I + III } \\ 14 & \text { I + III } \\ 14 \mathrm{a} & \text { I + III }+81 \\ 16 & 81+\text { III }\end{array}$

to many other antibiotics useful for treatment: about $90 \%$ were resistant to all aminoglycosides, $82.5 \%$ to erythromycin, $42 \%$ to clindamycin and $49 \%$ to pefloxacin. Resistance to co-trimoxazole, fusidic acid and rifampicin $(9,12$ and $12 \%$ respectively) was higher in comparison to methicillin-sensitive strains $(0 \cdot 3$, $2 \cdot 4$ and $2 \cdot 7 \%$ respectively). Resistance of the methicillin-sensitive strains against erythromycin was about $10 \%$ and pefloxacin $5 \%$ and gentamicin was the most active aminoglycoside with only $2 \%$ of resistant strains.

According to the hospital, resistance to some antibiotics (e.g. oxacillin, kanamycin, erythromycin) varied greatly, mainly due to persistent strains of the same type (as described earlier), showing an identical antibiotic pattern. For instance, in hospital $\mathrm{E}$, resistance to oxacillin reached $37.5 \%$ of the strains; however, of the 32 isolates tested, 12 isolates of the same type (zymotype 6), recovered from the same patient during 23 months, were resistant to oxacillin.

Resistance to the antibiotics tested was roughly higher for persistent strains of Group 1 patients in comparison to strains of Group 3 patients. 
Epidemiology of Staphylococcus aureus

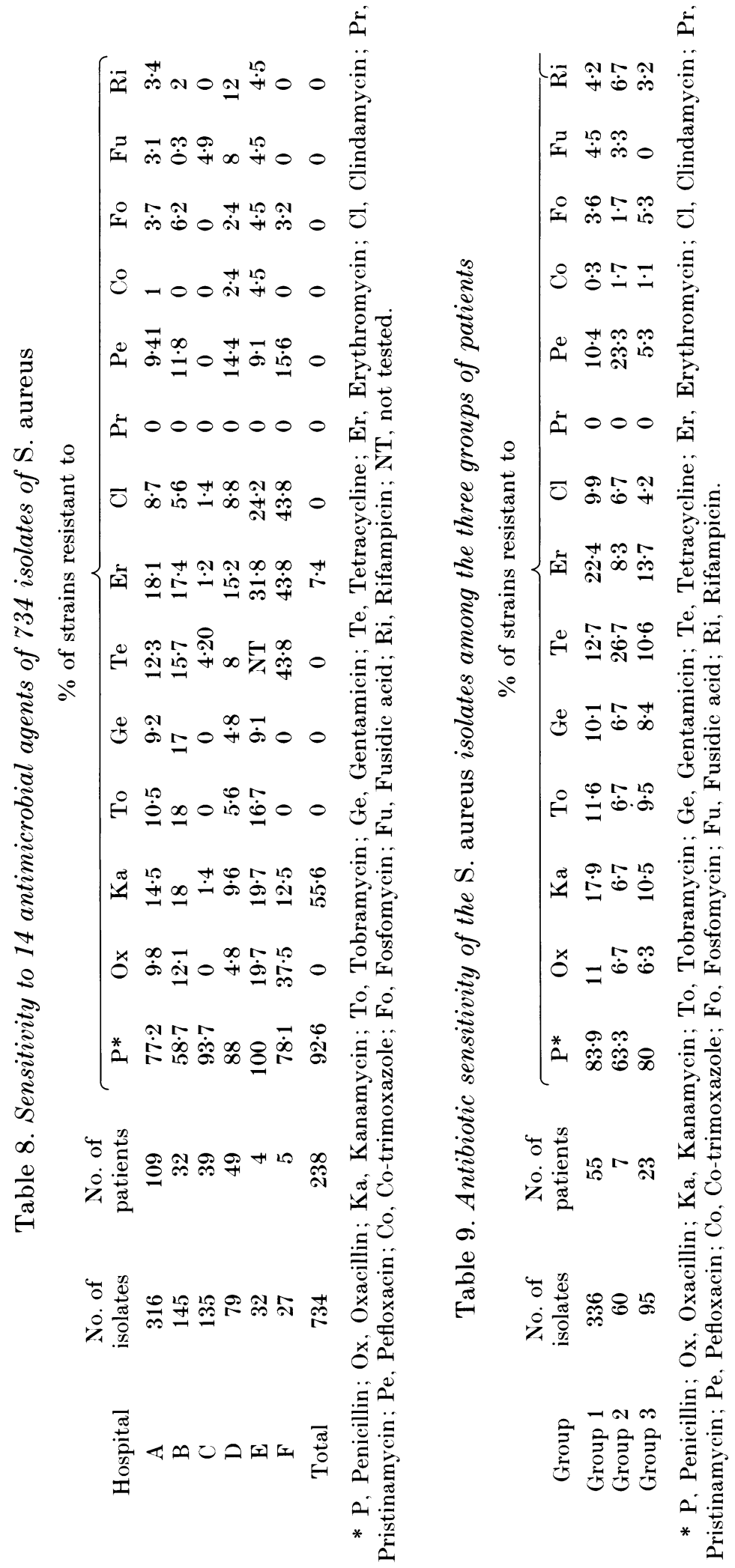




\section{DISCUSSION}

Respiratory infections play a major role in reducing pulmonary function in cystic fibrosis patients. Staphylococcus aureus alone is the initial bacterial pathogen but it later becomes associated with $P$. aeruginosa $[2,3]$. The use of epidemiological markers to type bacteria is important for conducting surveys of infections and can help to distinguish between reinfection and persistent infection and it can also be used to detect cross infections and type the strains associated with a disease [9-11, $26]$.

The 734 isolates of $S$. aureus analysed in the present study displayed 34 different zymotypes. No specific zymotype was associated with cystic fibrosis: zymotype 14 , which is the common zymotype, accounted for only $15 \%$ of the strains. The frequencies of the major zymotypes were also not significantly different $(P>0.5)$ from the frequencies of the same zymotypes in strains that were not from cystic fibrosis patients $[12,25]$. The overall genotypic diversity for esterases was greater than in previous studies $[12,25]$. Statistical analysis showed no difference in the frequencies of the zymotypes from each of the hospitals, except for zymotype 6 , which was encountered more frequently in hospital D. Zymotype 6 is closely associated with methicillin-resistance [12, 13, 25], indeed zymotype 6 accounts for $68-77 \%$ of the methicillin-resistant French strains. Only three methicillinsensitive strains of zymotype 6 have been found; those strains were penicillinsensitive but carried the same resistance to aminoglycosides and tetracycline as most of the French methicillin-resistant strains [12]. Strains of zymotype 6 are considered to be responsible for epidemic hospital-acquired infections [11, 12]. In the present study, the zymotype 6 strains found were all methicillin-resistant. Many of the strains were non-typable by phage $(33 \cdot 4 \%)$. As described previously [9], group III was the major lytic group and no specific phage type of $S$. aureus was associated with cystic fibrosis. The $S$. aureus strains isolated from cystic fibrosis patients belong to a wide range of types, and apart from the zymotype 6 strains, are similar to strains acquired outside hospitals [6].

Most of the isolates $(79 \%)$ had capsular polysaccharide types 8 or 5 , and $64 \%$ of them had a capsular polysaccharide type 8 . Similar results were obtained by Albus and co-workers for $S$. aureus strains isolated from cystic fibrosis patients and from healthy individuals [18]. There was a good correlation between capsular type and zymotype in the present study, corroborating the findings for other clinical isolates of $S$. aureus $[25,26]$.

Esterase electrophoretic typing indicated that $S$. aureus persisted for long periods in $73 \%$ of the patients (group 1 and 2 ) followed for at least 6 months. All the patients had a single persistent strain at any one time, except for three of them who had two persistent strains at the same time. Although phage typing is often unsatisfactory because its typability is lower than other typing methods $[6,9,26]$, a combination of phage type, capsular type and zymotype reliably delineated persistent strains in 36 patients. Indeed, the phage type did not change in those strains throughout the study. However, consecutive isolates that were the same type according to zymotype and capsular type, had different phage types in $\mathbf{1 3}$ patients and were not typable in 20 patients. Whether those later consecutive isolates are identical strains remains to be clarified by another typing technique, 
such as DNA fingerprinting of chromosomal DNA by pulsed-field gel electrophoresis [26]. Goering and colleagues [9] studied 34 cystic fibrosis patients with $S$. aureus positive cultures, and found that 6 patients had persistent infection (for up to 10 months) on the basis of plasmid and phage type. The present results also indicate that strains of $S$. aureus can persist for long periods.

The ability of $S$. aureus to interchange has been shown in only $27 \%$ of the patients (group 3). However, a strain isolated from one patient at the beginning of the study reappeared at the end of the study with three markers identical. Strains reappeared in seven other group 3 patients based on capsular type and esterase electrophoretic type. Goering and colleagues [9] observed cycles of carriage, loss, and reinfection in 2 of the 6 patients with persistent infection. It is also possible that double colonization prevented detection of the persistent strains. The isolates should be examined by genome typing to clarify these points.

Although it has not been clearly demonstrated that the capsular antigens of $S$. aureus induce protective immunity [26], the observation that a high percentage of strains isolated from cystic fibrosis patients has a type 8 or 5 capsular polysaccharide is encouraging for the development of an effective capsular vaccine to prevent repetitive bronchopulmonary infections.

Bauernfeind [5] reported that only netilmicin and glycopeptides were active against all the 179 strains isolated from 107 cystic fibrosis patients. Activity of the other antibiotics tested, including the most frequently used as co-trimoxazole, was impaired by resistance. Of the 179 strains, $11.7 \%$ were methicillin-resistant. In our study about $10 \%$ of the strains were methicillin-resistant. Resistance to the antibiotics tested varied greatly from one hospital to another, therefore the number of antibiotics available for therapy and prophylaxy depends on each hospital. However, $40 \%$ of the strains remained fully sensitive to all antibiotics tested except to penicillin. Pristinamycin was active on all the isolates and only $1 \%$ of the isolates were resistant to co-trimoxazole, an antibiotic widely used for treatment in these hospitals. Persistent strains of group 1 patients appeared to be more resistant to antibiotics than the varying strains of group 3 patients; however, clinical correlations are needed to provide a better understanding of the persistence of the strains.

The results of this study could contribute to the elaboration of a rational approach to the prophylaxis and therapy of staphylococcal infections in cystic fibrosis patients.

\section{ACKNOWLEDGEMENTS}

This work was supported by grants from the Association Française de lutte contre la Mucoviscidose. We thank C. Gaillard and N. Hautier for technical help and C. Gillet for typing the manuscript.

\section{REFERENCES}

1. Bauernfeind A. Bertele RM, Harms K, et al. Qualitative and quantitative microbiological analysis of sputa of 102 patients with cystic fibrosis. Infect $1987 ; 15: 270-7$.

2. Friend PA. Pulmonary infection in cystic fibrosis. J Infect $1986 ; 13: 55-72$.

3. Gilligan PH. Microbiology of airway disease in patients with cystic fibrosis. Clin Microbiol Rev $1991: 4: 35-51$. 
4. Hoiby N. Haemophilus influenzae, Staphylococcus aureus, Pseudomonas cepacia and Pseudomonas aeruginosa in patients with cystic fibrosis. Chest 1988; 94: 97-103.

5. Bauernfeind A, Przyklenk B, Matthias C, Jungwirth R, Bertele RM, Harms K. Selection of antibiotics for treatment and prophylaxis of staphylococcal infections in cystic fibrosis patients. Infect $1990 ; 18: 126-30$.

6. Hoff GE, Hoiby N. Staphylococcus aureus in cystic fibrosis: antibiotic sensitivity and phage types during the latest decade. Acta Path Microbiol Scand 1975; 83 : 219-25.

7. Marks MI. Clinical significance of Staphylococcus aureus in cystic fibrosis. Infect $1990 ; 18$ : $53-6$.

8. Guggenbichler JP, Schmeeberger J. Antimicrobial chemotherapy in patients with cystic fibrosis. Infect $1987 ; 15: 397-402$.

9. Goering RV, Bauernfeind A, Lenz W, Przyklenk B. Staphylococcus aureus in patients with cystic fibrosis : an epidemiological analysis using a combination of traditional and molecular methods. Infect 1990; 18: 57-60.

10. Hoiby N. Epidemiological investigations of the respiratory tract bacteriology in patients with cystic fibrosis. Acta Path Microbiol Scand 1974; 82: 541-50.

11. Bouvet A, Fournier JM, Audurier A, Branger C, Orsoni A, Girard C. Epidemiological markers for epidemic strains and carrier isolates in an outbreak of nosocomial oxacillinresistant Staphylococcus aureus. J Clin Microbiol 1990; 28 : 1338-41.

12. Branger C, Goullet P. Esterase electrophoretic polymorphism of methicillin-sensitive and methicillin-resistant strains of Staphylococcus aureus. J Med Microbiol 1987; 24: 275-81.

13. Branger C, Goullet P. Genetic heterogeneity in methicillin-resistant strains of Staphylococcus aureus revealed by esterase electrophoretic polymorphism. J Hosp Infect 1989; 14: 125-34.

14. Arbeit RD, Karakawa WW, Vann WF, Robbins JB. Predominance of two newly described capsular polysaccharide types among clinical isolates of Staphylococcus aureus. Diagn Microbiol Infect Dis $1984 ; 2: 85-91$.

15. Hochkeppel HK, Braun DG, Vischer W, et al. Serotyping and electron microscopy studies of Staphylococcus aureus clinical isolates with monoclonal antibodies to capsular polysaccharide types 5 and 8 . J Clin Microbiol $1987 ; 25$ : 526-30.

16. Karakawa WW, Fournier JM, Vann WF, Arbeit R, Schneerson RS, Robbins JB. Method for serological typing of the capsular polysaccharides of Staphylococcus aureus. J Clin Microbiol $1985 ; 22: 445-7$.

17. Sompolinsky D, Samra Z, Karakawa WW, Vann WF, Schneerson R, Malik Z. Encapsulation and capsular types in isolates of Staphylococcus aureus from different sources and relationship to phage types. J Clin Microbiol $1985 ; 22$ : 828-34.

18. Albus A, Fournier JM, Wolz C, et al. Staphylococcus aureus capsular types and antibody response to lung infection in patients with cystic fibrosis. J Clin Microbiol 1988; 26 : 2505-9.

19. Blair JE, Williams REO. Phage typing of staphylococci. Bull WHO $1961 ; 24: 771-84$.

20. Goullet P. An esterase zymogram of Escherichia coli. J Gen Microbiol 1973; 77 : 27-35.

21. Boutonnier A, Nato F, Bouvet A, et al. Direct testing of blood cultures for detection of the serotype 5 and 8 capsular polysaccharides of Staphylococcus aureus. J Clin Microbiol 1989; 27: 989-93.

22. Nei M. Estimation of average heterozygosity and genetic distance from a small sample of individuals. Genetics 1978; 89: 583-90.

23. Selander RK, Caugant DA, Ochman H, Musser JM, Gilmour MN, Whittam TS. Methods of multilocus enzyme electrophoresis for bacterial population genetics and systematics. Appl Environ Microbiol 1986; 51: 873-84.

24. Acar J, Bergogne-Bérézin E, Brogard JM, et al. Communiqué du Comité de l'Antibiogramme de la Société Française de Microbiologie. Pathol Biol 1993; 41 : 741-8.

25. Branger C, Goullet P, Boutonnier A, Fournier JM. Correlation between esterase electrophoretic types and capsular polysaccharide types 5 and 8 among methicillinsusceptible and methicillin-resistant strains of Staphylococcus aureus. J Clin Microbiol 1990; 28: $150-1$.

26. Schlichting C, Branger C, Fournier JM, et al. Typing of Staphylococcus aureus by pulsed field gel electrophoresis, zymotyping, capsular typing, and phage typing: resolution of clonal relationships. J Clin Microbiol $1993 ; 31: 227-32$.

27. Fournier JM. Staphylococcus aureus. In: Cryz SJ, ed. Vaccines and immunotherapy. New York: Pergamon Press, 1991 : 166-77. 